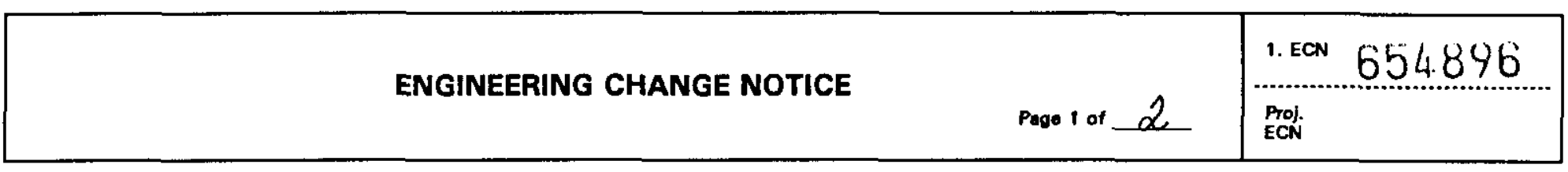

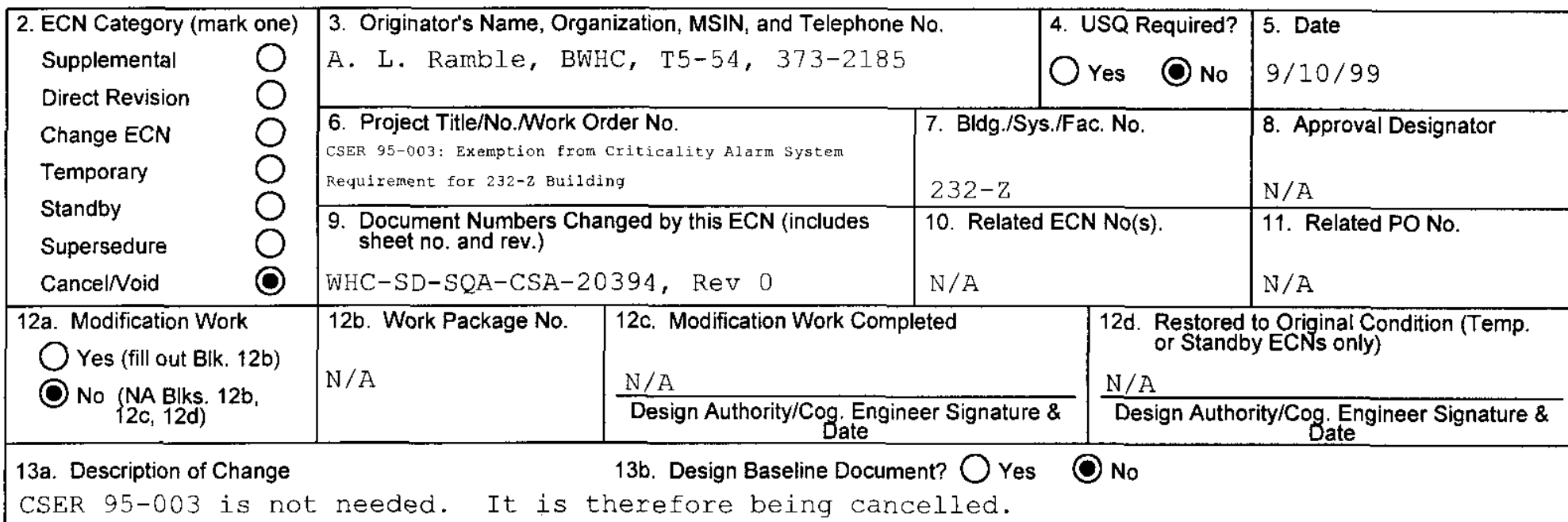

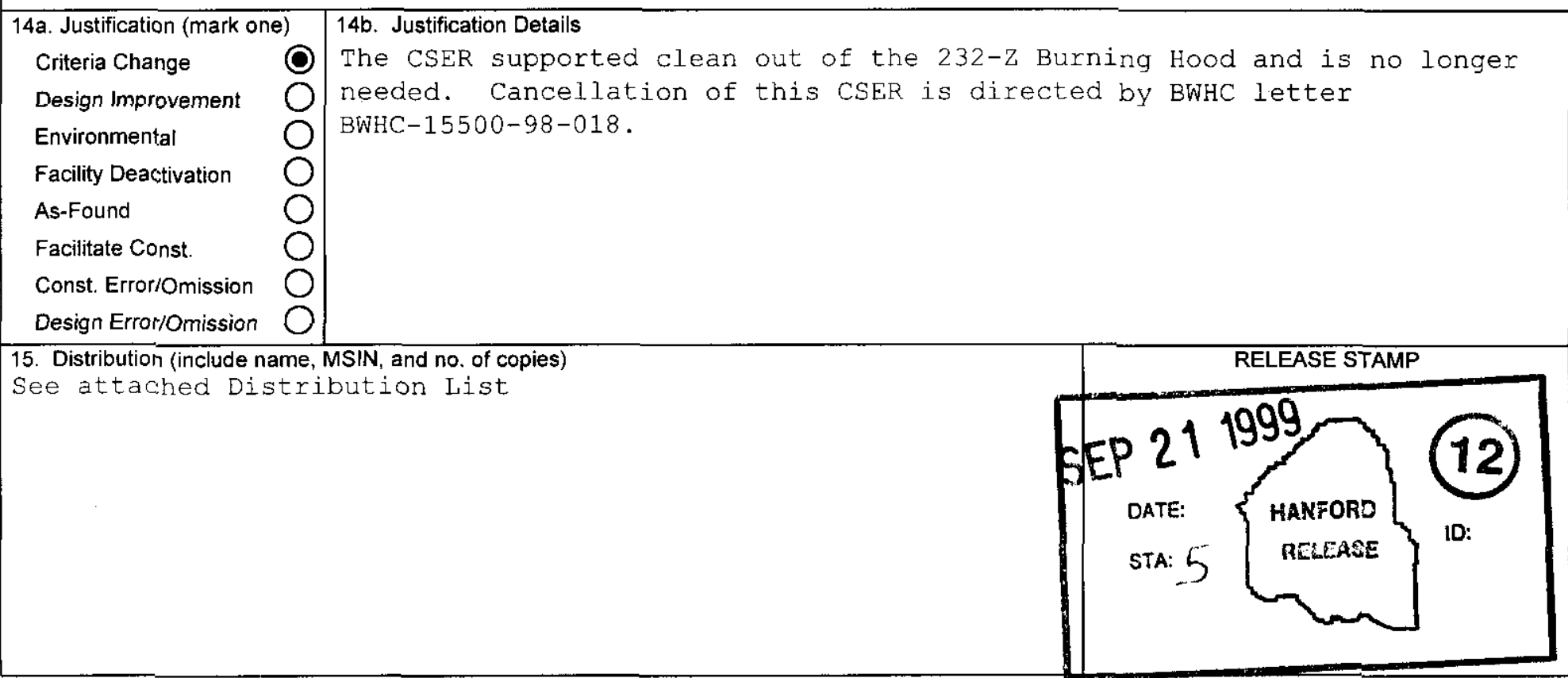




\section{ENGINEERING CHANGE NOTICE}

16. Design Verification Required

\section{Yes \\ No}

17. Cost Impact

ENGINEERING

Additional $\bigcirc \$$

Savings $\bigcirc \$$
Page 2 of 2

CONSTRUCTION

Additional $\bigcirc \$$

Savings $\bigcirc \$$
1. ECN (use no. from pg. 1)

654896

18. Schedule Impact (days)

Improvement

Delay

19. Change Impact Review: Indicate the related documents (other than the engineering documents identified on Side 1) that will be affected by the change described in Block 13. Enter the affected document number in Block 20 .

SDD/DD

Functional Design Criteria

Operating Specification

Criticality Specification

Conceptual Design Report

Equipment Spec.

Const. Spec.

Procurement Spec.

Vendor Information

OM Manual

FSAR/SAR

Safety Equipment List

Radiation Work Permit

Environmental Impact Statement

Environmental Report

Environmental Permit $\square \quad$ Seismic/Stress Analysis

Stress/Design Report

Interface Control Drawing

Calibration Procedure

Installation Procedure

Maintenance Procedure

Engineering Procedure

Operating Instruction

Operating Procedure

Operational Safety Requirement

IEFD Drawing

Cell Arrangement Drawing

Essential Material Specification

Fac. Proc. Samp. Schedule

Inspection Plan

Inventory Adjustment Request

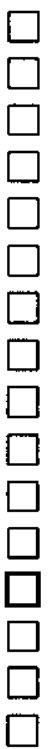

Tank Calibration Manual

Health Physics Procedure

Spares Multiple Unit Listing

Test Procedures/Specification

Component Index

ASME Coded Item

Human Factor Consideration

Computer Software

Electric Circuit Schedule

ICRS Procedure

Process Control Manuą/Plan

Process Flow Chart

Purchase Requisition

Tickler File

(2)

20. Other Affected Documents: (NOTE: Documents listed below will not be revised by this ECN.) Signatures below indicate that the signing organization has been notified of other affected documents listed below.

\section{Signature}

Design Authority M. E. Shaw $75-507 / 25$ Sand $4 / 1 / 49$

Cog. Eng. A. I. Ramble T5-54 CHella

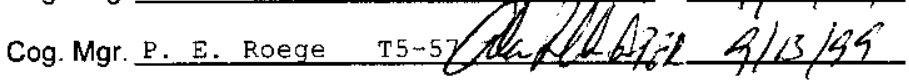

QA

Safety

$$
\text { D. A. Conniers }
$$

Environ.

Other

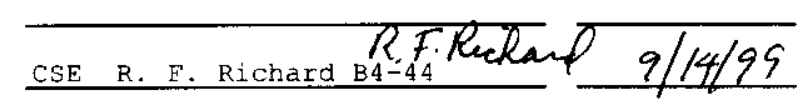

Signature

Date

Design Agent

PE

QA

Safety

Design

Environ.

Other

\section{DEPARTMENT OF ENERGY}

Signature or a Control Number that tracks the Approval Signature

ADDITIONAL 


\title{
CSER 95-003: EXEMPTION FROM CRITICALITY ALARM SYSTEM REQUIREMENT FOR 232-Z BUILDING
}

\author{
A. L. Ramble \\ B \& $W$ Hanford Company \\ Richland, WA 99352 \\ U.S. Department of Energy Contract DE-AC06-96RL13200

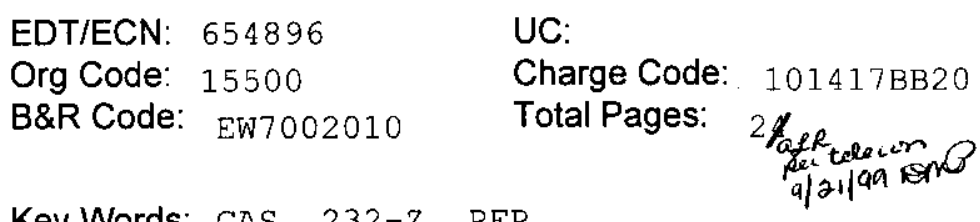 \\ Key Words: CAS, $232-2$, PFP
}

Abstract: This CSER is no longer needed so it is being cancelled

TRADEMARK DISCLAIMER. Reference herein to any specific commercial product, process, or service by trade name, trademark, manufacturer, or otherwise, does not necessarily constitute or imply its endorsement, recommendation, or favoring by the United States Government or any agency thereof or its contractors or subcontractors.

Printed in the United States of America. To obtain copies of this document contact: Document Control Services, P.O. Box 950, Mailstop H6-08, Richland WA 99352, Phone (509) 372-2420; Fax (509) 376-4989.

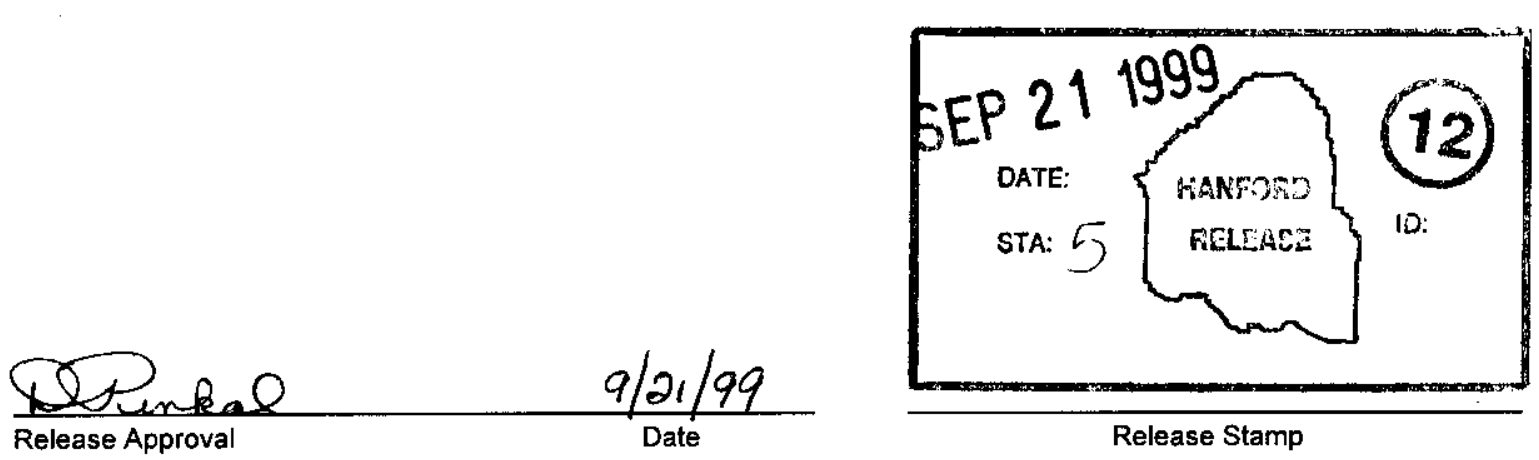




\section{RECORD OF REVISION}

(1) Document Number

HNF

wHe-SD-SQA-CSA-20394 a.2Q pertelecion $9 / 21199$ on 6

Page 1

(2) Title

CSER 95-003: Exemption from Criticality Alarm System Requirement for 232-z Building

Change Control Record

(3) Revision

(4) Description of Change - Replace, Add, and Delete Pages

(7)

$0 \quad$ Intial release EDT \# 605991 dated, May 18, 1995

\begin{tabular}{l|l} 
RS 1 & Cancel document WHC-SD-SQA-CSA-20394 per ECN
\end{tabular} 654896
Authorized for Release

\begin{tabular}{l|l} 
(5) Cog. Engr. & (6) Cog. Mgr. Date
\end{tabular}

EM Miller AL Ramble

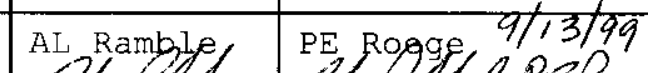

\begin{tabular}{l|l|l|l|}
\hline & & 4 & \\
\hline & & & \\
\hline
\end{tabular}




\section{DISTRIBUTION SHEET}

To

Distribution

\section{Project Title/Work Order}

CSER 95-003: Exemption from Criticality Alarm System Requirement for 232-z Building

\section{Name}

$B \notin W$ Hanford.

S.E. D.A. Conners D

A. L. Ramble

R. D. Redekopp

P. E. Roege

M. E. Shaw

DOE-RL

S. J. Altschuler

L. T. Nirider

Fluor Daniel Hanford

S. T. Almodovar

Fluor Daniel Northwest

K. D. Dobbin

E. M. Miller

R. F. Richard

H. Toffer

Central Files (Orig. +2)

Docket Files (2 copies)

\section{From \\ BWHC}

\begin{tabular}{|l|l|l|}
\multicolumn{1}{|l}{} & Page 1 of 1 \\
\cline { 2 - 3 } System Requirement for & Date $9 / 10 / 99$ \\
\cline { 2 - 3 } & EDT No. \\
\cline { 2 - 3 } & ECN No. 654896 \\
\hline
\end{tabular}

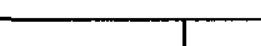

MSIN

Text With All Attach.

T5-11

T5-54

T5-15

T5-15

T $5-54$

Attach./ Only

EDT/ECN Only 